\title{
Modificaciones a la Leche del Programa Nacional de Alimentación Complementaria (PNAC) en Chile. 2009
}

\author{
CARLOS CASTILLO D. ${ }^{1}$, PAULINA BALBOA C. ${ }^{2}$, XIMENA RAIMANN T. ${ }^{3}$ y \\ RAMA DE NUTRICIÓN DE LA SOCIEDAD CHILENA DE PEDIATRÍA \\ 1. Nutriólogo Pediatra, Instituto de Nutrición y Tecnología de los Alimentos (INTA), Universidad de Chile. \\ 2. Pediatra, Departamento de Pediatría, Facultad de Medicina, Campus Norte, Universidad de Chile. \\ 3. Nutrióloga Pediatra, Presidenta Rama de Nutrición, Sociedad Chilena de Pediatría.
}

\begin{abstract}
Changing the Quality of Milk of the National Complementary Food Program in Chile, 2009

The National Complementary Food Programs have been one of the stratregies applied for preventing the protein-energy undernutrition and some specific nutrient deficiencies, during the last decades in Chile. To provide a powdered cow's milk to the underprivileged families has been one targets for the first years of life, which includes the fortification with iron, zinc, copper and vitamin C. The evident improvement in recent years of nutritional markers (prevalence of protein- malnutrition, deficiencies of $\mathrm{Fe}, \mathrm{Zn}$ and $\mathrm{Cu}$ ) requires to reassess the Programs. Some possible ways for improving the quality of milk to be provided are discussed, on the basis of avoiding the interference of exclusive breast milk.

(Key words: Nutrition, program, PNAC, food, undernutrition).

Rev Chil Pediatr 2009; 80 (6): 508-512
\end{abstract}

\section{RESUMEN}

Los Programas de Alimentación Complementaria para enfrentar la desnutrición y carencias nutricionales específicas de la población más vulnerable, tienen varias décadas de desarrollo en Chile. La entrega de una leche de vaca en polvo $\left(\mathrm{Purita}^{\mathrm{R}}\right)$ ha sido uno de los pilares en los primeros años de vida, estando fortificada en la última década con hierro, zinc, cobre y vitamina C. La evidente mejoría en años recientes de los indicadores nutricionales para estas edades (prevalencia de desnutrición, deficiencia de hierro, zinc y cobre) exige revisar esta parte del Programa. Se discuten aquí algunas formas de mejorar la calidad de la leche a entregar, manteniendo la premisa de no inteferir con la promoción de la lactancia materna exclusiva. (Palabras clave: Nutrición, programa, alimentación, PNAC, desnutrición).

Rev Chil Pediatr 2009; 80 (6): 508-512

Trabajo recibido el 20 de marzo de 2009, devuelto para corregir el 25 de abril de 2009, segunda versión rl 12 de junio de 2009, aceptado para publicación el 30 de septiembre de 2009.

Correspondencia a:

Carlos Castillo-Durán

E-mail: ccastd@med.uchile.cl 


\section{Antecedentes}

Desde inicios del siglo XX ha habido esfuerzos de establecer programas de entrega de alimentos en Chile a los niños en riesgo de problemas nutricionales (en especial desnutrición), incluyendo leche y otros alimentos.

En la década de los 80 se efectuaron estudios que justificaran un producto lácteo más acorde con los problemas nutricionales del momento, los que incluían, además de una desnutrición en disminución, una alta prevalencia de deficiencias nutricionales específicas, en especial $\mathrm{Fe}, \mathrm{Zn}$ y $\mathrm{Cu}$. La sugerencia de cambiar la leche de vaca entera en polvo por una leche modificada en su contenido de proteínas, grasas, hidratos de carbono y micronutrientes no fue aceptada en esa época por el Ministerio de Salud, optándose por instaurar desde 1997 una leche de vaca entera en polvo, fortificada con $\mathrm{Fe}, \mathrm{Zn}$ y $\mathrm{Cu}$, además de vitamina $\mathrm{C}$ para aumentar la absorción del hierro (LPF).

En las últimas 2 décadas se ha observado una disminución y prácticamente una desaparición de la desnutrición del lactante; también ha ido disminuyendo el nivel de pobreza extrema que afectaba a grupos importantes de la población. Junto a la LPF y una mejoría de los programas de fortificación con hierro y ácido fólico de la harina de trigo, se ha observado una disminución drástica de la prevalencia de anemia por deficiencia de hierro en lactantes, desde $25-30 \%$ a cifras inferiores al $8 \%$; la deficiencia de zinc también parece haber disminuido a prevalencias semejantes.

La nueva información científica exige que los programas de alimentación se adecuen al perfil epidemiológico nutricional actual. Es así como hay evidencias suficientes para avanzar en un buen aporte de algunos nutrientes no considerados previamente: ácidos grasos esenciales, incluyendo los ácidos grasos omega-6 ácido araquidónico (AA) y omega-3 docosahexaenoico (DHA); vitamina $\mathrm{D}$, ante la posibilidad de deficiencia en grupos de la población infantil que viven en zonas australes o nacidos con bajo peso de nacimiento. Por otra parte el exceso de aporte de proteínas que entrega la leche de vaca entera sumada a otros alimentos, puede estar contribuyendo a problemas nutricionales por exceso, incluyendo la obesidad.

\section{Leche Materna, Leches Adaptadas y Leche Purita Fortificada}

La leche materna debiera ser el alimento exclusivo para el lactante menor de seis meses y acompañada de alimentación complementaria al menos hasta el año de edad. Cuando esto no es posible se debe recurrir a fórmulas lácteas derivadas de la leche de vaca. En Chile se dispone de fórmulas comerciales adaptadas de inicio destinada a los menores de 6 meses y de continuación para los mayores de 6 meses. Estas fórmulas han modificado sus nutrientes en cantidad y calidad de tal manera de acercarse a la composición de la leche materna.

El Ministerio de Salud (MINSAL) a través de su Programa Nacional de Alimentación Complementaria, entrega actualmente durante el primer año de vida $2 \mathrm{Kg} / \mathrm{mes}$ de leche en polvo entera de vaca fortificada con hierro, vitamina $\mathrm{C}$, zinc y cobre, (LPF). En caso de aportarla al lactante menor de 6 meses se recomienda diluirla al 7,5\%, agregarle aceite de soya o canola al $2 \%$ y azúcar o maltodextrina al $2,5 \%$; para lactantes mayores de 6 meses la LPF se recomienda seguir diluyéndola al $7,5 \%$ pero con aporte de $5 \%$ de cereal y $2,5 \%$ de azúcar o maltodextrina.

Las fórmulas adaptadas de inicio y LPF preparada para los menores de $6 \mathrm{~m}$, tienen similar aporte de energía, entre 65 y $68 \mathrm{Kcal} /$ $100 \mathrm{ml}$ de fórmula, parecido al aporte de la leche materna (LM) y que está dentro de la recomendación del comité de expertos de la ESPGHAN (Tabla 1).

Sin embargo, el aporte proteico de la fórmula con LPF aún diluida al 7,5\% es mayor que el aportado por la leche materna y las leches adaptadas, lo que lleva a una carga renal de solutos aumentada. La composición proteica de la leche de vaca (LV) es diferente. Tiene una relación proteína del suero/caseína de 20/80 a diferencia de las leches adaptadas de inicio que tienen una relación de 60/40, permitiendo una mejor digestibilidad de la proteína y que el aporte proteico y aminoacídico se asemeje al de la 
Tabla 1. Aporte nutricional de leche materna y formulas lácteas por $100 \mathrm{kcal}$

\begin{tabular}{lrcrrr}
\hline Nutriente & Leche materna & $\begin{array}{c}\text { *LPF 7,5\% } \\
\text { sacarosa } \mathbf{2 , 5} \% \\
\text { aceite soya2\% }\end{array}$ & $\begin{array}{c}\text { **Fórmulas } \\
\text { de inicio }\end{array}$ & $\begin{array}{c}\text { *LPF 7,5\%, } \\
\text { cereal 5\%, } \\
\text { sacarosa 2,5\% }\end{array}$ & $\begin{array}{r}\text { **Fórmulas de } \\
\text { continuación }\end{array}$ \\
\hline Energía kcal/dL & 69 & 65,2 & $65-68$ & 66,0 & $67-71$ \\
Proteínas g & $1,15-1,3$ & 2,9 & $1,8-2,3$ & 2,7 & $2,2-3,4$ \\
Lípidos g & $4,3-7,2$ & 6,1 & $4,5-5,5$ & 2,1 & $4,1-5,5$ \\
A. Linoleico mg & $463-985$ & 1656,4 & $746,3-1230$ & 44,0 & $597-1159$ \\
A. Linolénico mg & $29-58$ & 214,7 & $88,5-107,7$ & 28,0 & $28,2-98,5$ \\
DHA \% & $0,2-0,5$ & 0,0 & $0-0,4$ & 0,0 & $0-0,76$ \\
A. Araquidónico \% & $0,5-0,7$ & 0,0 & $0-1,1$ & 0,0 & $10,3-12,6$ \\
H. de carbono & 9,8 & 12,3 & $10,4-13,08$ & 14,5 & - \\
\hline
\end{tabular}

* Aporte nutricional de LPF obtenido de especificaciones técnicas publicado por Minsal

**Aportes de fórmulas lácteas obtenido de especificaciones de laboratorio

LM. El consumo de proteína de leche de vaca produce concentraciones más bajas de triptófano y cisteina; la proporción de estos aminoácidos es la mitad de la encontrada en la leche humana.

Si bien el perfil aminoacídico de las leches adaptadas se acerca más al de la LM, éstos no son equivalentes, ya que la proteína del suero difiere entre la LM y la LV. El aporte proteico de las fórmulas adaptadas es mayor que la LM para así poder aportar concentraciones séricas adecuadas de aminoácidos esenciales necesarios para un crecimiento adecuado.

El aporte total de lípidos es similar entre la LM, LPF preparada y las fórmulas adaptadas. La diferencia fundamental es en el tipo de ácidos grasos (AG). La calidad de los AG aportados por la LM dependen de la dieta de la madre; la LV es pobre en AG esenciales. La fórmula con LPF mejora con el aporte de aceite de soya o de canola, aceites con un leve mayor contenido de ácido linolénico (omega-3), además del ácido linoleico (omega-6). Si bien los RN pueden elongar y desaturar los AG esenciales a ácidos graso poliinsaturados de cadena larga o PUFA, tienen una baja bioconversión (1\%) de ácido linolénico a ácido docosahexanoico o DHA. Es necesario aportarlo preformado dado el alto requerimiento de DHA en los primeros meses por el rápido crecimiento cerebral. En los lactantes el aporte preformado de DHA se ha relacionado con mejor agudeza visual, mejor atención visual y mayor resolución de problemas. La FAO/OMS recomienda aportar en las fórmulas lácteas $0,38 \%$ de los $\mathrm{AG}$ como DHA y aportar por lo menos una cantidad 1,5 ó 2 veces más de ácido araquidónico (AA), ya que la falta de aporte de él se ha relacionado con menor crecimiento. El nivel de DHA que aporta la LM depende de la dieta materna y esto varía entre $0,2-0,5 \%$ de los AG. El nivel de aporte de las fórmulas adaptadas es muy variable $(0-0,4 \%$ de los $A G)$. La fórmula con LPF no aporta DHA ni AA.

El grupo internacional coordinado por ESPGHAN recomienda un aporte mínimo de hidratos de carbono de $9 \mathrm{~g} / 100 \mathrm{kcal}$ de fórmula considerando la necesidad de glucosa del cerebro; tanto la LPF preparada como las fórmulas adaptadas cumplen con ella. El grupo internacional no recomienda la adición de sacarosa ya que contiene fructosa, por el riesgo de secuela y muerte que pueda sufrir un lactante con intolerancia hereditaria a la fructosa. La LPF preparada contiene sacarosa, en su defecto se puede preparar con maltodextrina. Algunas fórmula adaptadas contienen sólo lactosa mientras que otras contienen además sacarosa y polímeros de glucosa.

Las fórmulas adaptadas de continuación para los lactantes mayores de 6 meses contienen mayor aporte proteico $(2,2-3,4 \mathrm{~g} / 100 \mathrm{kcal}) \mathrm{y}$ una relación caseína/proteína del suero 80/20, ya que la maduración digestiva permite una mejor digestión de la caseína, tienen un mejor desarrollado de las vías metabólicas de los 
aminoácidos. El aporte de energía, de hidratos de carbono y de lípidos es similar al de las fórmulas de inicio. El aporte de ácidos grasos esenciales puede ser aportado en la alimentación complementaria y existe controversia hasta cuando seguir suplementando con DHA. Según la opinión de expertos ésta se debiera extender hasta el año de edad, pero se puede realizar a través de la alimentación complementaria. Incluso la ESPGHAN concluye que fórmulas regulares de inicio cubren las necesidades nutricionales de los niños sobre los 6 meses y que no se necesita fórmulas de continuación.

\section{Funciones que pueden estar alteradas con el uso de la leche Purita fortificada.}

A- La LV no modificada tiene nutrientes como proteínas y minerales que están en cantidad excesiva con respecto a la leche materna. La LPF, aún en dilución al 7,5\% tiene un mayor contenido de proteínas que la leche materna; si se entrega en forma exclusiva el primer semestre o con el agregado de alimentación complementaria el segundo semestre, puede aumentar el riesgo de: a) deshidratación e hipernatremia en niños con cuadros febriles o diarrea debido a la alta carga renal de solutos dada por proteínas y minerales $(\mathrm{Na}, \mathrm{Cl}, \mathrm{K})$; b) mayor riesgo de obesidad. Las proteínas estimulan la secreción de IGF-1, la síntesis proteica y proliferación celular. El aumento de los niveles de IGF-1 puede acelerar el crecimiento y aumento de la masa muscular y también el tejido adiposo.

B- La LV tiene un bajo contenido de ácidos grasos esenciales omega-3 y omega- 6 y un alto contenido de ácidos grasos saturados. Se han realizado numerosos estudios en lactantes pequeños para evaluar el efecto de los aportes de DHA en el desarrollo del sistema visual. La evidencia actual apoya los beneficios de DHA y AA en el desarrollo de la agudeza visual en lactantes.

Dos estudios han evaluado el rol de LCPUFA en el desarrollo visual durante el segundo semestre de la vida, a través de fórmula o alimentación complementaria, observando una mejoría en aspectos de la visión comparados con los controles. Respecto a la influencia de LC- PUFA en el desarrollo cognitivo, aún la evidencia es controversial.

Otros efectos: se ha encontrado una asociación entre la suplementación de DHA y AA a las fórmulas infantiles y una menor presión arterial a los 6 años de edad.

Por lo tanto, si el lactante no recibe leche materna, estos AGCL debieran adicionarse a las fórmulas de lactantes. La LPF no está fortificada con ellos.

E1 DHA debiera ser un $0,2 \%$ a un $0,5 \%$ de los ácidos grasos y el AA adicionado debe ser al menos igual al de DHA. Parece recomendable continuar la provisión de ácidos grasos poliinsaturados de cadena larga durante el segundo semestre de la vida, pero las cantidades óptimas aún no han sido especificadas.

C- La vitamina D está en cantidad insuficiente en la leche de vaca y la LPF no se encuentra fortificada con ella. En el año 2003, la Academia Americana de Pediatría recomendó la ingesta diaria de 200 UI de vitamina D en lactantes, niños y adolescentes sanos, para prevenir su deficiencia. Basados en la evidencia de nuevos trabajos clínicos, esta recomendación fue modificada recientemente volviendo a las antiguas $400 \mathrm{UI}$ diarias. Las fórmulas para lactantes contienen 40 UI de vitamina D por cada $100 \mathrm{ml}$ (reconstitución habitual).

D- La necesidad de agregar otros componentes (aceite, sacarosa, cereales) aumenta la manipulación en la preparación de la mamadera o biberón. El aporte de sacarosa debiera estar postergado hasta el segundo año o tercer año de vida, ante la evidencia que puede estar interfiriendo en los mecanismos de regulación del apetito y de la apetencia por el sabor dulce.

Las alternativas a considerar frente a un eventual cambio de la LPF incluyen: entrega de una leche adaptada comercial; entrega de una leche adaptada comercial, pero con mantención del nombre de leche Purita; entrega de una leche de vaca "modificada"; duración eventual hasta los 12 meses de edad. En esta decisión del MINSAL debiera contemplarse todos los efectos favorables de la tuición en la entrega de estos productos por la estructura pública de Salud y los potenciales efectos desfavorables 
sobre el estímulo a la lactancia materna de todas las fórmulas.

\section{Referencias}

1.- Koletzo B, Baker S, Cleghorn G, et al: Global standards for the composition of infant formula: Recommendations of the ESPGHAN Coordinated Internacional Expert Group. JPGN 2005; 41: 584-99.

2.- Picciano MF: Nutrient composition of human milk.
Pediatr Clin North Am 2001; 48: 53-67.

3.- Lien E: Infant Formula with increased concentrations of $\alpha$-lactalbumin. Am J Clin Nutr 2003; 77: 1555S$8 \mathrm{~S}$.

4.- Wagner CL, Greer FR and the section on breastfeeding and Committee on Nutrition: Prevention of rickets and vitamin D deficiency in infancy, children and adolescents. Pediatrics 2008; 122: 1142-52.

5.- Fleischer Michaelsen K: Cows' milk in complementary feeding. Pediatrics 2000; 106 (Suppl 5): 1302-3. 